\title{
Zona Metropolitana del Valle de México: neoliberalismo y contradicciones urbanas
}

EMILIO PRADILLA GOBOS*

\section{Resumen}

En 32 años de aplicación de políticas neoliberales en México, la Zona Metropolitana del Valle de México, una de las cuatro mayores de América Latina, ha sufrido grandes cambios demográficos, económicos, sociales y territoriales. Ha crecido intensamente en población y extensión; su economía se ha desindustrializado y terciarizado con dominio de la informalidad, ha perdido dinamismo de crecimiento y es la mayor concentración de pobres del país. Su territorio se dispersa en la periferia y se re-construye internamente por la acción del capital inmobiliario-financiero, se reestructura a partir de una trama de corredores terciarios, su movilidad la domina el automóvil privado, y muestra una intensa segregación socio-territorial. Fragmentada en lo político-administrativo, las políticas territoriales aplicadas a la metrópoli son descoordinadas, contradictorias, pragmáticas, coyunturales, no planeadas, y se orientan fundamentalmente a facilitar las intervenciones del capital, particularmente el inmobiliario-financiero. La conflictividad de la metrópoli genera continuamente movimientos urbanos que ahora incluyen a capas medias y altas que defienden la habitabilidad de sus barrios de las intervenciones combinadas del capital inmobiliario y los gobiernos locales. La metrópoli está en crisis, pero ni el disperso movimiento social, ni los pragmáticos partidos políticos tienen un proyecto urbano alternativo para superarla.

Palabras clave: Zona Metropolitana del Valle de México. Neoliberalismo. Cambios Territoriales. Crisis Metropolitana. Políticas Públicas.

*Universidad Autónoma Metropolitana, Unidad Xochimilco (México). 


\title{
Metropolitan area of the Valley of Mexico: neoliberalism and urban contradictions
}

\begin{abstract}
Following 32 years of implementation of neoliberal policies in Mexico, the Metropolitan Area of the Valley of Mexico, one of the four largest metropolitan areas in Latin America, has undergone significant demographic, economic, social and territorial changes. It has grown strongly in population and extension; its economy has de-industrialized and grown in outsourcing with predominance of informality, it has lost dynamism of growth and comprises the largest concentration of poor in the country. Its territory spreads towards periphery and is internally rearranged by the action of the real estate and financial capital, it is restructured over a network of tertiary urban corridors, its mobility is dominated by the private car, and it shows a strong socio-spatial segregation. Being politically and administratively fragmented, the territorial policies applied to the metropolis are uncoordinated, contradictory, pragmatic, circumstantial, unplanned, and mainly aimed to facilitating capital interventions, particularly the real estate and financial. The contentious character of the metropolis continuously generates urban movements that now include middle and upper classes who advocate for living conditions of their neighbourhoods against the combined interventions of real estate capital and local governments. The metropolis is under crisis, but neither the dispersed social movement, nor the political parties have an alternative urban project to overcome it.
\end{abstract}

Keywords: Metropolitan Areas of the Valley of Mexico. Neoliberalism. Territorial changes. Metropolitan crisis. Public policies. 


\section{Introducción}

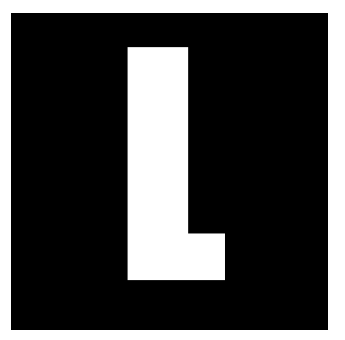

a Zona Metropolitana del Valle de México (ZMVM), es hoy la mayor concentración urbana de México y una de las cuatro metrópolis más pobladas de América Latina, junto con las regiones metropolitanas de Buenos Aires, Rio de Janeiro y Sao Paulo. La ZMVM está formada por la Ciudad de México ${ }^{1}$, capital del país y su núcleo estructurador histórico, así como por 59 municipios conurbados del Estado de México y 1 del Estado de Hidalgo (CONAPO, 2007).

A una escala mayor, la ZMVM se ha convertido en el núcleo central de una extensa ciudad región (Pradilla, 2009, p.263), formada por 6 grandes zonas metropolitanas ${ }^{2}$ y aproximadamente 270 Unidades Político-Administrativas (UPA), pueblos y ciudades ubicados entre las metrópolis, asentadas sobre 7 Entidades Federativas ${ }^{3}$ en la región central del país (FEECIME, 2000: 16).

En las últimas tres décadas, la ZMVM ha experimentado intensos cambios urbanos determinados por las reformas para la implantación del patrón neoliberal de acumulación de capital que se han aplicado en México desde 1983 (Guillén, 1997: 97-148), en varias oleadas de distinta intensidad ${ }^{4}$. Los procesos más significativos en términos de los cambios territoriales han sido: la privatización de lo público, desde las grandes empresas paraestatales hasta las infraestructuras y servicios urbanos (Pradilla, 1990, 1994); la privatización del suelo rural, en particular el periférico a las ciudades (Pra-

\footnotetext{
${ }^{1}$ En lo político-administrativo, la Ciudad de México está dividida en 16 demarcaciones territoriales denominadas Delegaciones.

${ }^{2}$ Zonas metropolitanas de Cuernavaca-Cuautla, Puebla-Tlaxcala, Pachuca, Querétaro-San Juan del Río, Toluca-Lerma y Valle de México.

${ }^{3}$ Estados de Morelos, Puebla, Tlaxcala, Hidalgo, Querétaro, México, y Ciudad de México.

${ }^{4}$ Las coyunturas más importantes de implantación de reformas neoliberales han sido los gobiernos de Carlos Salinas (1988-1994), Ernesto Zedillo (1994-2000), y Enrique Peña (2012-2018).
} 
dilla, 1993b); la creciente mercantilización de los ámbitos y objetos urbanos (Pirez, 2014); las asociaciones público-privadas en la producción y gestión de las obras públicas; la apertura del mercado interno a la libre circulación de mercancías y capitales mediante múltiples tratados internacionales de libre comercio; la desindustrialización y terciarización informal de las economías urbanas (Márquez y Pradilla, 2008); la proliferación de objetos urbano-arquitectónicos como centros comerciales, mega-conjuntos, ámbitos urbanos cerrados, etcétera (Pradilla, 2010); el debilitamiento de la planeación urbana y el nuevo protagonismo del mercado de suelo e inmuebles (Pradilla, 2009: 195-219). Estos procesos, generalizados, se han combinado para transformar estructuralmente a las ciudades mexicanas, incluyendo la ZMVM, de la misma manera que han transformado desigualmente a otras ciudades de América Latina (Pradilla, 2014).

Los actores fundamentales en estos cambios metropolitanos han sido los gobiernos locales convertidos en facilitadores subsidiarios de la acción del capital privado (Pradilla, 2010, 2014, 2015'b), y el capital inmobiliario-financiero nacional y trasnacional asociado, dominante en la producción de la ciudad (Harvey, 1990, 2009, 2014; Pradilla, 2010 y 2014), en razón de la larga duración de la producción inmobiliaria y la extensión del ciclo de recuperación del capital invertido (Jaramillo, 2009: 101-105). En este trabajo expondremos sintéticamente las determinaciones fundamentales de estos cambios territoriales en el caso de la ZMVM.

\section{La expansión demográfica y física}

El crecimiento demográfico de la ZMVM ha sido constante, aunque desigual en el tiempo, desde que se inició el desborde de su núcleo, la ciudad de México DF, sobre los municipios del contiguo Estado de México en los años cuarenta del siglo XX. Entre 1940 y 1970, la metrópoli cre- 
ció a tasas anuales promedio superiores al 5,00 \% por la combinación de una intensa inmigración de población de otras áreas del país, en particular desplazada del campo, y el crecimiento natural de su propia población (cuadros 1 y 2); posteriormente, la tasa de crecimiento declinó debido al menor impacto relativo de la inmigración y a la disminución de la tasa de crecimiento natural. Desde 1950, fueron los municipios colindantes al DF que se integraron a la ZMVM, los que tuvieron mayor crecimiento poblacional, mientras que él DF se convirtió en exportador neto de población hacia su periferia metropolitana; más precisamente, las UPA centrales de la metrópoli expulsan población hacia las periféricas. Desde el año 2000, los municipios conurbados superan en población a la Ciudad de México, y la diferencia aumenta con el tiempo debido al desigual crecimiento poblacional de las dos partes de la metrópoli.

Cuadro 1

\begin{tabular}{|l|c|c|c|c|c|c|c|c|}
\hline \multicolumn{7}{|c|}{ Población de la Ciudad de México y la ZMVM } \\
\hline & $1940^{\wedge}$ & $1950^{\wedge}$ & \multicolumn{1}{c|}{$1960^{\wedge}$} & \multicolumn{1}{c|}{$1970^{\wedge}$} & \multicolumn{1}{c|}{$1980^{\wedge}$} & \multicolumn{1}{c|}{$1990^{\wedge}$} & \multicolumn{1}{c|}{$2000^{\wedge}$} & \multicolumn{1}{c|}{$2010^{\wedge \wedge}$} \\
\hline DF & $1,757,530$ & $3,050,442$ & $4,870,876$ & $6,874,165$ & $8,831,079$ & $8,235,744$ & $8,605,239$ & $8,851,080$ \\
\hline $\begin{array}{l}\text { Municipios } \\
\text { conurbados }\end{array}$ & 199,969 & 289,943 & 590,799 & $2,220,307$ & $4,064,528$ & $7,328,051$ & $9,791,438$ & $11,265,762$ \\
\hline ZMVM & $1,957,499$ & $3,340,385$ & $5,461,675$ & $9,094,472$ & $12,895,607$ & $15,563,795$ & $18,396,677$ & $20,116,842$ \\
\hline
\end{tabular}

Fuentes:^ INEGI, "Censo General de Población y Vivienda" DF y Edomex, INEGI, 1940-1990

^^ CONAPO, "Delimitación de las zonas metropolitanas de México", CONAPO, 2005

^^^ INEGI, "Censo de Población y Vivienda 2010"

Cuadro 2

\begin{tabular}{|l|c|c|c|c|c|c|c|c|}
\hline \multicolumn{7}{|c|}{ Tasa de Crecimiento Demográfico en la Ciudad de México y la ZMVM } \\
\hline & $1930-1940$ & $1940-1950$ & $1950-1960$ & $1960-1970$ & $1970-1980$ & $1980-1990$ & $1990-2000$ & $2000-2010$ \\
\hline DF & - & 5.67 & 4.79 & 3.5 & 2.54 & -0.7 & 0.44 & 0.28 \\
\hline $\begin{array}{l}\text { Municipios } \\
\text { conurbados }\end{array}$ & - & 3.79 & 7.38 & 14.16 & 6.23 & 5.6 & 2.94 & 1.41 \\
\hline ZMVM & $4.75^{*}$ & 5.49 & 5.04 & 5.23 & 3.55 & 1.69 & 1.69 & 0.9 \\
\hline
\end{tabular}

Fuente: Elaboración propia con base en los datos del cuadro "Población de la ciudad de México y la ZMVM)

*Nota: Esta tasa de crecimiento corresponde al cambio de la Ciudad de México a la ZMVM 
La explicación de la polarización del crecimiento poblacional en la metrópoli, en particular su componente migratorio, la encontramos en el hecho de que la Ciudad de México, capital del país y sede de los poderes federales, y posteriormente la zona metropolitana en su conjunto fueron el motor del proceso de industrialización por sustitución de importaciones de México entre 1930 y 1970, y la concentración y centralización del capital generó un importante mercado laboral y expectativas de mejores condiciones de vida para los inmigrantes, lo cual atrajo a las migraciones campesinas (Garza, 1985; Pradilla, 1993á: cap. II).

El intenso crecimiento demográfico y un patrón histórico de poblamiento de relativamente baja densidad inmobiliaria y poblacional (Pradilla, 2011), han llevado a una expansión física más que proporcional a la de la población (Cuadro 3), siguiendo ciclos sucesivos de expansión-consolidación-expansión, como señalan Duhau y Giglia (2008: 116-117).

\section{Cuadro 3}

Superficie ocupada en la ZMVM, 1980-2010

\begin{tabular}{lcccc}
\hline \multicolumn{1}{c}{ ZMVM } & 1980 & 1990 & 2000 & 2010 \\
\hline Nueva Sup. Ocupada (ha) & - & $12,777.55$ & $41,427.13$ & $106,177.08$ \\
Sup. Total ocupada (ha) & $60,975.93$ & $73,753.48$ & $115,180.61$ & $221,357.69$ \\
Población & $12,895,607$ & $16,266,602$ & $19,126,982$ & $20,791,292$ \\
\hline
\end{tabular}

Fuente: Elaboración propia con información de INEGI 2010 y CONAPO 2005

Tomado de Pradilla (coord.) y otros, 2015a: cap. 2.

Este patrón expansivo ha sido notoriamente intenso en los períodos 1990-2000 y, sobre todo, 2000-2010 debido al impacto territorial de la combinación de dos reformas neoliberales aprobadas en 1991-1992: las reformas a la legislación agraria federal que permitieron a los ejidatarios 
y comuneros $^{5}$ de núcleos agrarios periféricos a la ZNVM la venta de sus tierras, antes inalienables, a las empresas inmobiliarias (Pradilla, 1993b); y las reformas a la legislación de los organismos estatales de vivienda para los trabajadores (INFONAVIT, FOVISSSTE) los cuales dejaron de operar como organizadores de su producción para convertirse en organismos de financiamiento hipotecario para que sus beneficiarios adquieran vivienda producida por el sector inmobiliario privado (Puebla 2002). Así, se avanzó en la mercantilización de la vivienda pública en el país (Pirez, 2014). Desde entonces, las grandes inmobiliarias construyeron cientos de miles de mini-viviendas de interés social en grandes conjuntos ${ }^{6}$ alejados del perímetro urbano y dispersos sobre la periferia norte y nor-oriente metropolitana, donde adquirían tierra rural a bajo costo. El resultado ha sido una expansión urbana dispersa, como archipiélago, mostrada en el mapa 1. Hoy, la superficie ocupada por la metrópoli es tres veces la de 1990, aunque el aumento de la población ha sido mucho menor, originando una caída notoria de la densidad demográfica general.

\footnotetext{
${ }^{5}$ La propiedad ejidal y la comunal fueron formas sociales de propiedad rural instituidas en la reforma agraria surgida de la Revolución Mexicana de la segunda década del siglo XX.

${ }^{6}$ Entre 1999 y 2011, las empresas inmobiliarias construyeron 256 conjuntos habitacionales con 564.832 viviendas.
} 
Mapa 1

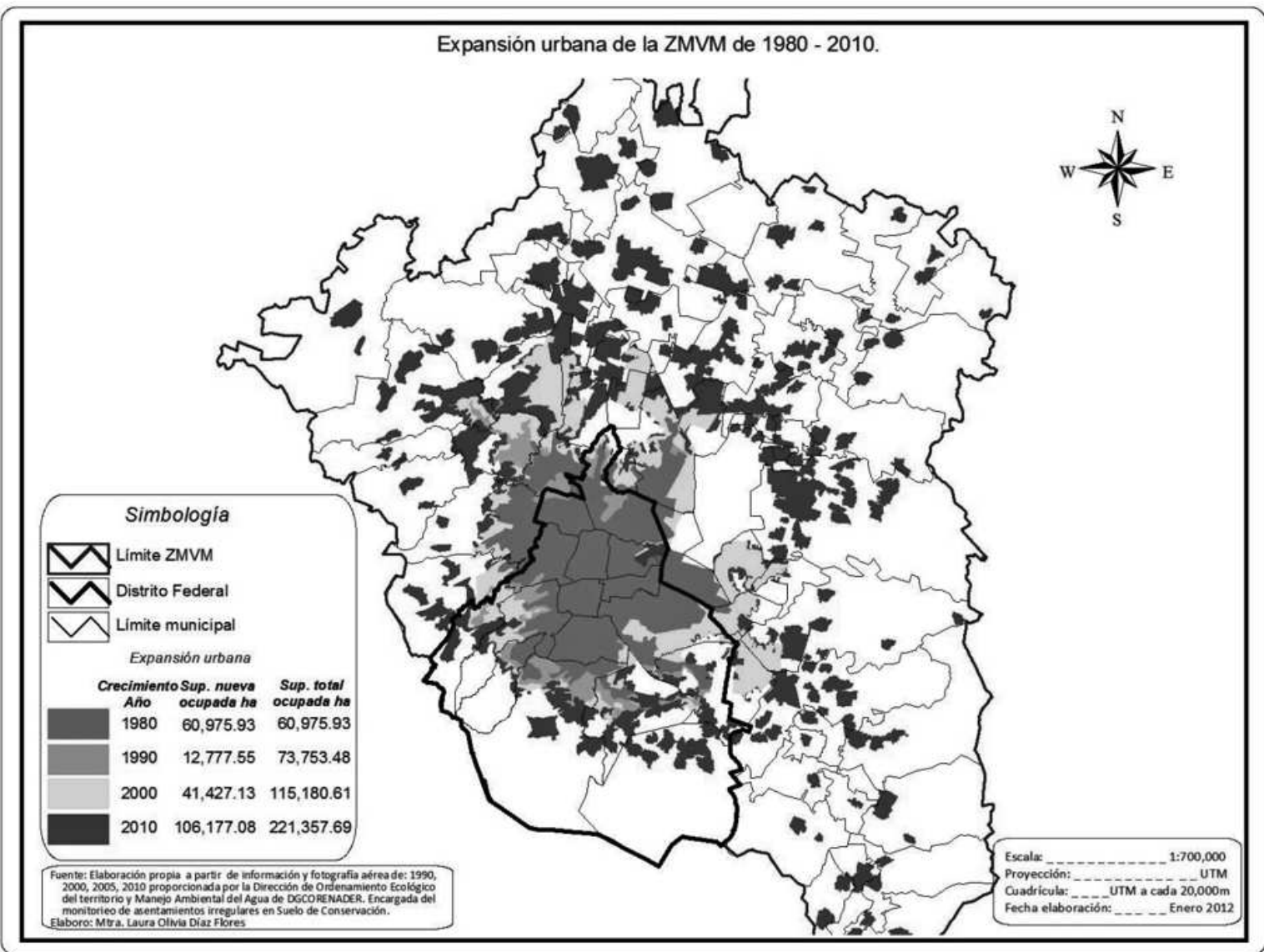

Tomado de Pradilla (coord.) y otros, 2015a, cap. 2.

La desindustrialización relativa y absoluta

Desde 1983, la aplicación paulatina de las reformas económicas que llevaron a la implantación del patrón neoliberal de acumulación de capital en México, y sus nuevas condiciones de inserción en la fase actual de la mundialización capitalista, en particular la apertura al flujo de mercancías y capitales del exterior mediante múltiples tratados de libre comercio, sobre todo el Tratado de Libre Comercio de América del Norte (TLCAN), con Canadá y Estados Unidos, cuya operación inició en 1994, han generado notorios cambios estructurales en la economía metropolita- 
na. El más importante ha sido la desindustrialización relativa y absoluta de la metrópoli (Márquez y Pradilla, 2008), que se enmarca en la tendencia de México a sufrir desigualmente una desindustrialización relativa prematura, debida a: la baja productividad del sector fabril; las altas tasas de interés en el mercado especulativo y abierto de capitales; la apreciación de la moneda ante las divisas internacionales; y la baja competitividad de sus precios de producción en el marco del proceso neoliberal de apertura comercial internacional (Salama, 2012).

La desindustrialización relativa respecto al país ha sido muy notoria. El DF fue el territorio más importante en la industrialización entre 1930 y 1970; desde entonces, ha disminuido continuamente su participación relativa en el total nacional: en 1970 generó el 32,20\% del Producto Interno Bruto de la Industria Manufacturera (PIBIM) nacional, pero su participación descendió hasta 10,86\% en 2009 (-21,34 \%); esta participación tuvo dos caídas muy fuertes: entre 1980 y 1993, y entre 2002 y 2003 cuando cayó por debajo de la del Estado de México en su conjunto (Cuadro 4). El Estado de México7, que incluye a 59 municipios conurbados en la metrópoli, perdió peso industrial relativo muy moderadamente: bajo de $17,51 \%$ en 1970 , a $14,07 \%$ en 2009 (- 3,44\%).

\footnotetext{
${ }_{7}$ En este rubro, carecemos de estadísticas a nivel municipal que nos permitan establecer la participación de los 59 municipios conurbados del Estado de México en la producción industrial nacional.
} 
Sociologias, Porto Alegre, ano 18,no 42, mai/ago 2016, p. 54-89

Cuadro 4

\begin{tabular}{|c|c|c|c|c|c|c|c|c|c|c|c|}
\hline \multicolumn{12}{|c|}{$\begin{array}{l}\text { Participación del DF, Estado de México y Región Centro en el Pib de la Industria } \\
\text { manufacturera nacional, 1970-2009 }\end{array}$} \\
\hline Año & 1970 & 1975 & 1980 & 1985 & 1993 & 1994 & 1995 & 1996 & 1997 & 1998 & 1999 \\
\hline $\mathrm{DF}$ & 2 & 29.82 & 29.46 & 24.71 & 20.85 & 20.31 & 19.68 & 8.67 & 18.94 & 8.81 & 18.6 \\
\hline & & .37 & 18.07 & 19.11 & 17.39 & & 16.19 & 16.49 & & 6.2 & 16.13 \\
\hline 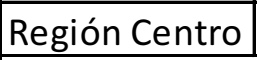 & 56.41 & & 56.44 & & 48.63 & & & & & & 46.06 \\
\hline \multicolumn{2}{|l|}{ Año } & 2000 & 2001 & 2002 & 2003 & 2004 & & 2006 & & & 2009 \\
\hline DF & & 18.62 & 18.06 & 18.27 & 10.97 & 10.74 & 10.82 & 10.75 & 10.52 & 10.47 & 10.86 \\
\hline Edomex & & 16.03 & 16.52 & 16 & 13.46 & 13.52 & 13.63 & 13.42 & 13.64 & 13.63 & 14.07 \\
\hline Región Centro & & 45.83 & 45.79 & 45.56 & 37.38 & 36.82 & 37.15 & 36.58 & 37.1 & 40.25 & 37.6 \\
\hline
\end{tabular}

Fuente: Elaboración propia con base en el Banco de Información Económica (BIE), producto interno bruto por entidad federativa, INEGI.

Un análisis ${ }^{8}$ de los siete Censos Económicos levantados entre 1980 y 2008 por el Instituto Nacional de Estadística, Geografía e Informática $^{9}$ (INEGI), que reúnen las estadísticas de los sectores formales, muestra un proceso de desindustrialización absoluta de la ZMVM en su conjunto, mucho más severa en la parte del DF que en los municipios conurbados mexiquenses. La evolución de las variables principales de la industria durante este período de 28 años es elocuente (Pradilla (coord.) y otros, 2015aㅗ : cap. 3).

El número de establecimientos industriales en el DF creció a una tasa anual promedio del 0,03 \%, en los municipios conurbados del Estado de México creció al 5,44 \%, y en la ZMVM en su conjunto creció al $1,83 \%$. Pero este desempeño positivo no es corroborado por el de

\footnotetext{
${ }^{8}$ Un análisis estadístico e interpretativo amplio de este material se encuentra en Pradilla (coord.) y otros, 2015a , cap. 3, libro en proceso de publicación en la Universidad Autónoma Metropolitana.

${ }^{9}$ Nos referimos a la serie de censos económicos XI a XVII realizados en 1980, 1985,1988, 1993, 1998, 2003 y 2008, por el INEGI, que incluyen datos para la Zona Metropolitana de la Ciudad de México, conformada por menos municipios conurbados que la ZMVM.
} 
otras variables. El personal ocupado en la industria en el DF disminuyó a una tasa anual promedio del $-2,57 \%$, creció al 0,73\% en los municipios conurbados, y cayó en el conjunto de la ZMVM al -1,36 \%. Al comparar estas dos variables podemos deducir que se produjo una disminución del tamaño en personal de los establecimientos, derivada de la reducción de la fuerza laboral por el incremento de la productividad del trabajo en el segmento moderno de la industria, pero también por la creación de muchas micro y pequeñas empresas artesanales, ya que el promedio de trabajadores por empresa se redujo en el período de 30,13 a 12,17 en la ZMVM en su conjunto.

Las remuneraciones totales del personal ocupado sufrieron un deterioro muy significativo en el período, pues cayeron en el DF a una tasa anual promedio de $-2,92 \%$, en los municipios conurbados cayeron al $-2,05 \%$, y en la ZMVM cayeron al $-2,58 \%$. Este es el resultado de la disminución del personal ocupado, y fundamentalmente de la política gubernamental y empresarial de contracción del salario real de los trabajadores impuesta mediante aumentos salariales anuales menores que la inflación, aplicada nacionalmente desde el inicio y a todo lo largo del período de 28 años, que ha llevado al salario mínimo a perder un 69,83 $\%$ de su valor real entre 1981 y 2012 (INEGI, 2013).

El indicador central para medir la trayectoria de la industria manufacturera es el Valor Agregado Censal Bruto, pues mide el valor que realmente se añade a los productos en un ámbito territorial dado. Este indicador disminuyó en el período analizado en el DF -2,21 \% en promedio amual, en los municipios conurbados cayó al -0,37 \%, y en la ZMVM al -1,45\% anual. Como se observa, la desindustrialización absoluta más intensa ha ocurrido en el DF, núcleo histórico de la metrópoli y polo industrial más importante del país en los años setenta. 
Las determinantes de esta desindustrialización absoluta y relativa de la metrópoli son múltiples y entrelazadas complejamente. Los gobiernos nacionales neoliberales entregaron el proceso de industrialización al "libre mercado" y dejaron de elaborar y aplicar políticas públicas para el desarrollo del sector. Al mismo tiempo, aplicaron una política muy activa de apertura del comercio exterior mexicano que, con la operación de múltiples tratados de libre comercio, particularmente el TLCAN, ha permitido el ingreso al país de productos manufacturados en condiciones de competencia muy desigual y desfavorable para los productos locales, particularmente para la pequeña y mediana empresas; igualmente, ha impulsado la sustitución de proveedores de insumos locales por extranjeros y desarticulado las cadenas de valor. La agresiva política china de comercio exterior ha jugado en el mismo sentido. Los ciclos recesivos de la economía mexicana de 1982, 1986, 1995, 2001 y 2009, causaron la desaparición de empresas industriales, sobre todo pequeñas y medianas. Por su parte, las grandes empresas trasnacionales exportadoras se han relocalizado en las áreas centro-norte y norte del país ${ }^{10}$, para acercarse territorialmente al mercado estadounidense, buscar mercados laborales con salarios más bajos que en el metropolitano, y evitar las deseconomías de aglomeración que se han formado en la ZMVM tales como los sobrecostos por la saturación del tráfico vehicular urbano y regional, las más estrictas regulaciones ambientales y los mayores costos laborales. Finalmente, a lo largo del período, los gobiernos federales y locales metropolitanos difundieron un discurso de promoción de la desconcentración económica e industrial de las tres grandes metrópolis mexicanas, y actuaron en consecuencia.

\footnotetext{
${ }^{10} \mathrm{El}$ caso de la industria de ensamblaje de automotores y sus proveedores de partes e insumos es paradigmático, pues se trasladó o instaló hacia el centro-norte y norte del país, abandonando totalmente la ZMVM.
} 
El resultado estructural más importante ha sido que la economía de la ZMVM ha perdido paulatinamente a su sector industrial, el más dinámico en términos de encadenamientos productivos y efectos multiplicadores internos y sobre el sector terciario, así como para la generación de empleo estable, adecuadamente remunerado y con acceso a la seguridad social (Márquez y Pradilla, 2008). Esta es una de las razones de que la metrópoli haya tenido a lo largo del período, tasas de crecimiento anual promedio del PIB menores y tasas de desempleo abierto mayores que la media nacional (Pradilla (coord.) y otros, 2015a․ 106 y 189). Aunque estas tendencias parezcan positivas para lograr menores desequilibrios regionales, profundizan los problemas sociales de los habitantes de la ZMVM.

Además del impacto de la desindustrialización sobre la distribución territorial del empleo y sus desplazamientos, ha aportado grandes extensiones de suelo urbano, en muchos casos localizado estratégicamente en la ciudad interior, para los procesos de terciarización formal, de producción de vivienda para sectores de ingresos medios y altos y de verticalización edilicia.

\section{La terciarización informal}

La caída de la participación relativa de la industria en la economía metropolitana durante el período 1980-2008, ha traído el aumento de la participación del sector terciario formal (comercio y servicios). Correlativamente con la desindustrialización absoluta, el crecimiento del sector comercial y de servicios ha sido muy intenso, dando lugar a que la economía metropolitana se haya terciarizado notablemente durante el período cubierto por los Censos Económicos analizados (Pradilla (COord.) y otros, 2015a. cap. 4). 
En este período, el número de establecimientos terciarios formales en la ZMVM creció a una tasa anual promedio de 3,70 \%, en el DF al 2,22 $\%$ y en los municipios conurbados al $6,75 \%$ anual promedio, mostrando un proceso muy intenso de desconcentración territorial y penetración terciaria en las áreas de vivienda intermedias y periféricas de la metrópoli, determinado por la concentración poblacional, los problemas de movilidad de la demanda, la distancia-tiempo a los emplazamientos anteriores y la estrategia de los oferentes. El crecimiento del personal ocupado en el sector terciario fue aún más intenso, pues aumentó en la ZMVM a una tasa anual promedio del 5,50 \%, en el DF al 4,94\%, y en los municipios conurbados al 7,84 \%; así, el crecimiento del número de establecimientos fue acompañado por el del número de empleados por establecimiento.

Las remuneraciones totales del personal ocupado crecieron a pesar de la austeridad salarial, debido al notorio incremento de su número, pero a tasas menores que este: en la ZMVM crecieron a una tasa anual promedio de 3,57 \%, en el DF al 3,59\%, y al 3,40 \% en los municipios conurbados. Finalmente, el crecimiento sostenido del Valor Agregado Censal Bruto valida la intensa terciarización: crece a una tasa anual promedio de 5,01 \% en la ZMVM; al 5,20\% en el DF, y al 3,38 \% en los municipios conurbados; la diferencia entre las dos partes de la metrópoli muestra una mayor productividad en el DF que en los municipios conurbados.

La terciarización de la economía formal, ha venido acompañada de la formación de un sector terciario informal de gran magnitud en el que se refugia el $48,9 \%$ de la población ocupada del DF y el $58,7 \%$ de la del Estado de México (INEGI, 2012): entre 5 y 6 millones de personas en la ZMVM. Una parte de esta masa de informales desarrolla su actividad de subsistencia en el comercio en la vía pública; según el Gobierno local, miembros de la Asamblea Legislativa del DF, y líderes de organizaciones de vendedores, en 2013 la cifra variaría entre 1 millón 200 mil y 
dos millones, distribuidos en los lugares de concentración de transeúntes y usuarios de servicios, sobre todo en el área central (La Jornada, 16-I2013; El Universal, 17-XII-2013). Estas cifras son aleatorias, pues no existe un censo de los vendedores callejeros en la metrópoli.

La polarización del sector terciario metropolitano entre una franja formal, moderna, tecnologizada y muy concentrada, orientada hacia el mercado empresarial y de consumo de los sectores de ingresos medios y altos, registrada en los censos económicos, y una amplia franja informal, atrasada, dispersa y de muy baja productividad, dirigida hacia el mercado de los sectores de más bajos ingresos, se explica, de un lado, por la apertura internacional del mercado de capitales y mercancías, la presencia creciente de los grandes monopolios nacionales y trasnacionales en el comercio, los servicios y las finanzas, y su búsqueda de nuevos mercados en las áreas populares; y de otro, en presencia de la desindustrialización, por la incapacidad o desinterés del sector formal para absorber a la masa de población económicamente activa presente en el mercado laboral, y la búsqueda de los desempleados de formas de subsistencia en el comercio callejero, los servicios personales mal remunerados y las actividades delictivas.

La desindustrialización absoluta y relativa, y una terciarización dominada cuantitativamente por las formas de subsistencia de la informalidad, han dado lugar a una notoria pérdida del dinamismo económico metropolitano, a la caída de su productividad y al aumento del desempleo. En el período, la participación del DF en el Producto Interno Bruto Nacional (PIBN) disminuyó de 30,5\% a 17,5\% (-13.0\%); y la del Estado de México ${ }^{11}$ solo creció $+1,56 \%$, de $7,62 \%$ a 9,18\%, sin compensar la caída del DF en el total de la ZMVM. Esta tendencia decreciente se ha

\footnotetext{
${ }^{11}$ No disponemos de información estadística del PIB por municipios, lo que impide establecer el monto del producto de los municipios conurbados en la ZMVM; utilizamos como referencia el PIB del Estado de México, en la medida que este se genera mayoritariamente en esos municipios.
} 
mantenido porque desde 1975, tanto en períodos de recesión como de recuperación económica, el DF ha tenido tasas de crecimiento del PIB inferiores a la media nacional y a la del Estado de México, exceptuando las coyunturas de 1993, 2000 y 2002. El Estado de México ha mostrado tasas de crecimiento del PIB en ocasiones superiores y en otras inferiores a la media nacional (Cuadro 5).

Cuadro 5

\begin{tabular}{|l|c|c|c|c|c|c|c|c|c|c|c|c|c|c|c|}
\hline \multicolumn{10}{|c|}{ Participación del DF, Edo. De México y Región Centro en el PIB nacional (\%), 1970-2009 } \\
\hline Año & 1970 & 1971 & 1972 & 1973 & 1974 & 1975 & 1976 & 1977 & 1978 & 1979 & 1980 & 1985 & 1988 & 1993 & 1994 \\
\hline Región Centro & 43.00 & 44.40 & 44.00 & 43.90 & 43.70 & 435.00 & 43.90 & 43.70 & 43.60 & 43.80 & 42.10 & 39.90 & 40.70 & 42.40 & 24.10 \\
\hline DF & 27.50 & 30.50 & 29.50 & 29.20 & 28.50 & 26.10 & 28.10 & 27.80 & 27.60 & 27.60 & 25.10 & 20.90 & 21.30 & 23.90 & 23.70 \\
\hline Edo. De México & 8.62 & 7.62 & 7.96 & 8.21 & 8.57 & 10.20 & 9.11 & 9.20 & 9.30 & 9.48 & 9.79 & 11.10 & 11.40 & 10.30 & 10.30 \\
\hline Año & 1995 & 1996 & 1997 & 1998 & 1999 & 2000 & 2001 & 2002 & 2003 & 2004 & 2005 & 2006 & 2007 & 2008 & 2009 \\
\hline Región Centro & 41.10 & 41.50 & 41.80 & 41.60 & 41.70 & 41.20 & 41.10 & 41.40 & 40.30 & 39.10 & 39.30 & 39.00 & 34.50 & 33.00 & 35.10 \\
\hline DF & 23.10 & 22.90 & 23.00 & 22.50 & 22.50 & 22.70 & 23.20 & 23.20 & 22.70 & 21.80 & 21.60 & 21.50 & 17.30 & 16.90 & 19.50 \\
\hline Edo. De México & 10.00 & 10.30 & 10.60 & 10.70 & 10.70 & 10.10 & 10.00 & 9.64 & 9.02 & 8.83 & 9.00 & 8.86 & 8.88 & 8.81 & 9.18 \\
\hline
\end{tabular}

Fuente: Banco de información económica (BIE), producto Interno Bruto por entidad federativa. Participación porcentual de los estados en las actividades económicas del periodo 1970-2009. INEGI.

Sistemas de cuentas nacionales (SCNM). Un modelo de desagregación geográfica: Estimación del PIB por entidad federativa, 1970-1988. Nota: La región centro comprende entidades del DF, Hidalgo, Estado de México, Morelos, Puebla, Querétaro y Tlaxcala.

En este contexto de desindustrialización y terciarización, la economía de la metrópoli se ha orientado hacia la privatización y mercantilización de todo lo urbano, y a la acumulación de capital mediante una incesante expansión de la acción del sector inmobiliario-financiero en diferentes ámbitos territoriales metropolitanos.

\section{El capital inmobiliario-financiero y sus productos}

La inserción de México en la fase actual de la mundialización del capital ha abierto las puertas al capital inmobiliario-financiero trasnacional, que se ha ligado al nacional, para emprender una verdadera ofensiva de transformación edilicia de la metrópoli, desarrollada en múltiples frentes; 
para ello ha contado con políticas urbanas muy favorables, en muchos casos promocionales, de los gobiernos locales metropolitanos (Pradilla, 2015 ${ }^{\text {b). }}$

El inicio del proceso de re-construcción urbana desarrollado por el capital inmobiliario-financiero fue la construcción de centros y plazas comerciales. En un levantamiento concluido en julio de $2012^{12}$, se contaron 262 centros comerciales en la ZMVM, 245 de ellos fueron construidos después de 1981 en el período analizado; el número y el área de los centros comerciales construidos aumento notoriamente luego de 1991(Cuadro 6). Posteriormente a la realización del levantamiento, la construcción de centros comerciales ha continuado con gran intensidad. Inicialmente, los centros comerciales se construían en áreas pobladas por sectores de ingresos medios y altos, pero en los últimos años, como parte de la terciarización y desconcentración mercantil, se localizan también en áreas periféricas de población de ingresos bajos (Pradilla y otros, 2008; Mapa 2).

\section{Cuadro 6}

Centros Comerciales en la Zona Metropolitana del Valle de México por período

\begin{tabular}{|l|r|r|r|r|r|}
\hline PERíODO & \multicolumn{1}{c}{$\begin{array}{c}\text { Número de } \\
\text { Centros y plazas }\end{array}$} & \multicolumn{2}{c}{ Área comercial $\left(\mathrm{mts}^{2}\right)$} & \multicolumn{2}{c|}{ Número de locales } \\
\hline $1960-1980$ & 17 & 375,924 & 22,113 & 1,270 & 75 \\
\hline $1981-1990$ & 30 & 539,731 & 17,991 & 2,373 & 79 \\
\hline $1991-200$ & 115 & $2,207,108$ & 19,192 & 9,086 & 79 \\
\hline $2001-2012$ & 100 & $3,143,007$ & 31,430 & 8,876 & 89 \\
\hline TOTAL & 262 & $6,265,770$ & 23,915 & 21,605 & 82 \\
\hline
\end{tabular}

Centros comerciales en construcción

Pabellón Azcapotzalco, Azcapotzalco, Distrito Federal

Garden Mall, Álvaro Obregón, Distrito federal

Parque Toreo, Naucalpan, Estado de México

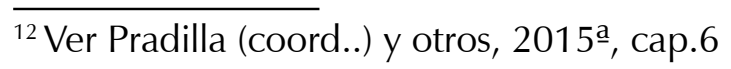


Desde 1992, basándose en las políticas federales privatizadoras del suelo rural de propiedad social ${ }^{13}$ y de la producción de vivienda pública antes señaladas, el capital inmobiliario-financiero detonó un proceso de expansión física sin precedentes de la metrópoli mediante la construcción de cientos de mega-conjuntos de mini-viviendas de interés social en la periferia norte y nor-oriente de la ZMVM con características de poca habitabilidad: alejadas del perímetro urbano, de muy pequeña dimensión, mala calidad constructiva, y carentes de servicios urbanos adecuados de transporte público, abasto, educación, salud, cultura, etc.; esta situación ha llevado a que más de un tercio de estas viviendas hayan sido abandonadas por sus "beneficiarios", o permanezcan sin comprador (Duhau, 2008; Eibenschutz y Goya, 2009; Mendiburu, 2011; Pradilla, 2015푸).

Al mismo tiempo, las empresas inmobiliarias están transformando la estructura urbana interior mediante intensos procesos de re-construcción en las áreas de antigua urbanización, que incluyen la realización de grandes proyectos de usos mixtos o intervenciones puntuales de construcción de torres de oficinas, hotelería, vivienda para sectores de ingresos medios y altos, y centros comerciales de diverso tamaño y orientados a distintos estratos sociales de mercado. Grandes proyectos como Santa Fe, la reconstrucción de Paseo de la Reforma e Insurgentes, el proyecto Mitikah, el Complejo Carso, el conjunto El Toreo, Polanco, son ejemplos de la acción del capital inmobiliario-financiero nacional y trasnacional. Una de las características de esta re-construcción es la verticalización, que permite reducir el peso por unidad de producto de las rentas del suelo urbano acumuladas en el precio elevado del terreno en áreas interiores de la metrópoli (Jaramillo, 2009).

\footnotetext{
${ }^{13}$ Nos referimos a la tierra rural bajo las formas de propiedad ejidal y comunal, fragmentada y alienable desde la contra-reforma agraria de 1991-1992.
} 
Solo con la información censal de 2020 podremos establecer los cambios en la distribución territorial de la población causados por estos procesos cuyo impacto no planificado es, en ocasiones, contrapuesto.

\section{La reestructuración interna de la metrópoli}

Los procesos de crecimiento demográfico y físico, aumento de distancias, terciarización y re-construcción inmobiliaria, han llevado a la metrópoli a transitar de su estructuración a partir de una centralidad única en el período de intensa metropolización (1940-1970), a una etapa transicional basada en centralidades múltiples jerarquizadas, y después de 1980, a una organizada a partir de una trama compleja de corredores urbanos terciarios que se han formado a lo largo de los ejes viales de más intenso tráfico de mercancías y personas tanto en las antiguas áreas centrales como en las delegaciones y municipios periféricos, desplazando de ellos a la población residente (Pradilla y Pino, 2004; Pradilla y otros, 2008). En 2012, la trama tenía 108 corredores de diferente extensión, densidad inmobiliaria, intensidad de ocupación terciaria y área de influencia territorial ${ }^{14}$ (Pradilla (coord.) y otros, 2015ª̣: cap. 6).

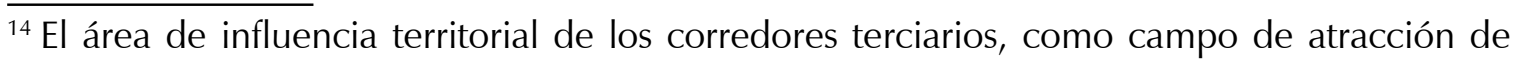
compradores, es local o barrial, de un área urbana significativa, o de partes amplias de la metrópoli o toda ella.
} 
Mapa 2

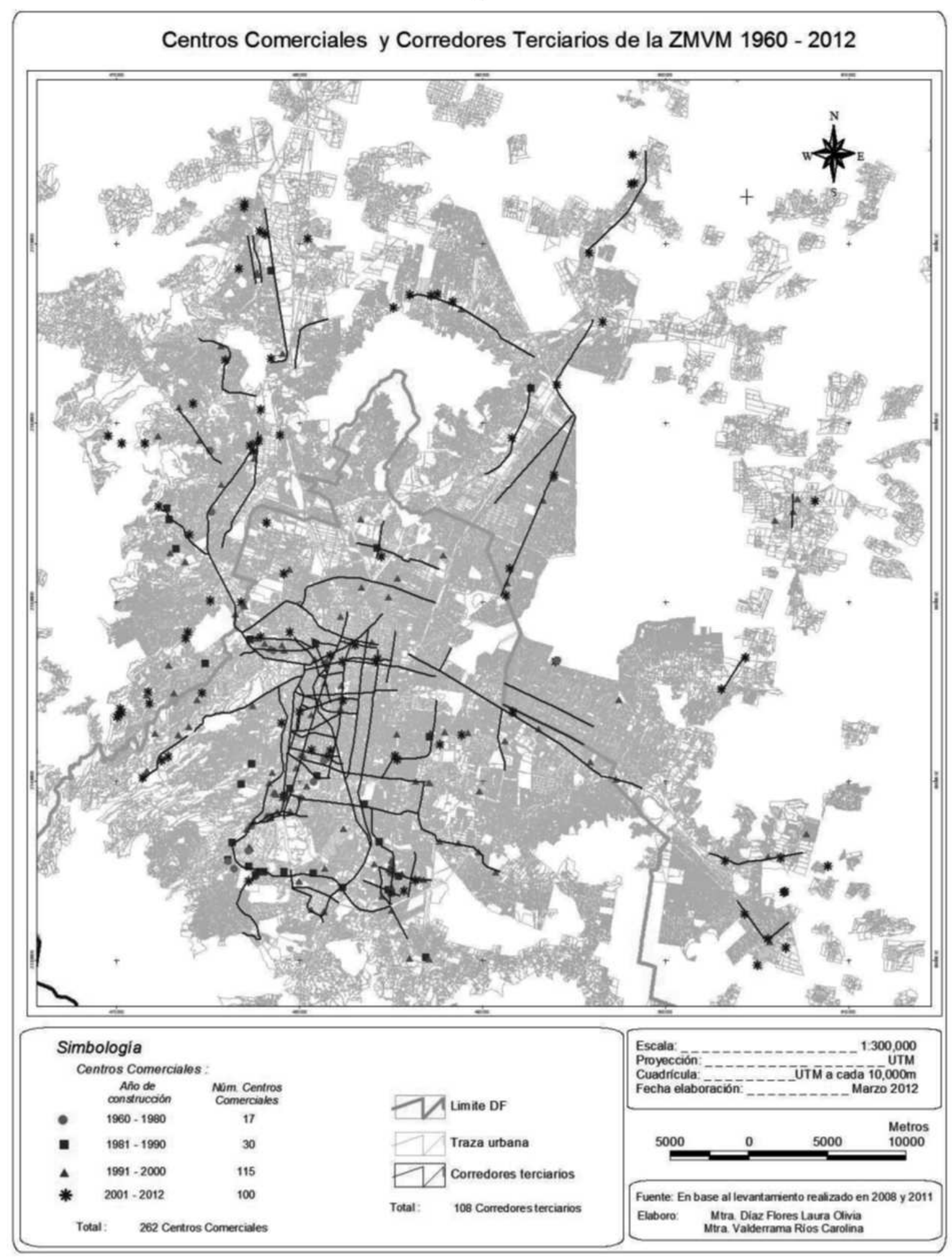


Las determinantes fundamentales de la proliferación y distribución territorial de estos corredores en la zona metropolitana han sido: a) la ubicación y trazo de los ejes de gran flujo de transporte de mercancías y pasajeros, sobre todo automóviles, modalidad dominante de movilidad por la intensa motorización de las últimas décadas; b) la dispersión de las zonas de residencia de la población metropolitana en un territorio cada vez más extenso, lo cual exigía la localización cercana del abasto de bienes y servicios a su ubicación, y ofrecía un mercado importante a sus proveedores, incluidas las cadenas de tiendas de autoservicio y departamentales; y c) el proceso de terciarización y desconcentración de la economía metropolitana. Los centros comerciales fueron adosándose a los corredores terciarios que les ofrecían economías de aglomeración, o detonaron su formación al localizarse sobre ejes de movilidad.

Aunque la trama de corredores terciarios es hoy mucho más densa en las áreas de más antigua urbanización (la centralidad expandida) que mantiene parte de su dinamismo, también se ha desarrollado en las delegaciones y municipios periféricos, diferenciándose en su forma y contenido según el estrato social residente o que usa las áreas de influencia y atracción.

\section{El automóvil privado y la saturación vial}

La extensión creciente de la metrópoli, que alarga el tiempo y hace más complejo el desplazamiento de la población, el déficit cuantitativo y cualitativo de los medios de transporte público, poco atractivos para los sectores de ingresos medios y altos, y las facilidades mercantiles otorgadas por la industria automotriz trasnacional en expansión, han impulsado un crecimiento acelerado de los automotores en la metrópoli; en treinta y cinco años, se multiplicaron más de 4,25 veces, pasando de cerca de 2 millones a casi 9 millones (cuadro 7), a un ritmo mayor que el crecimiento 
demográfico (1.56 veces), indicando un notorio incremento del grado de motorización; la gran mayoría son automóviles particulares, que consumen la mayor masa de combustibles y ocupan mayoritariamente la vialidad con su circulación y estacionamiento, pero transportan apenas a un tercio de las personas movilizadas diariamente. El automóvil es el medio de transporte dominante.

\section{Cuadro 7}

Automóviles registrados en circulación en la ZMVM

\begin{tabular}{|c|c|c|c|c|c|}
\hline & 1980 & 1990 & 2000 & 2010 & 2014 \\
\hline ZMVM & $2,091,930$ & $2,616,645$ & $3,381,382$ & $6,606,690$ & $8,894,628$ \\
\hline \multirow{2}{*}{$\begin{array}{c}\text { Tasa de Crecimiento } \\
\text { anual promedio }\end{array}$} & $1980-1990$ & $1990-2000$ & $2000-2010$ & $2010-2014$ \\
\cline { 2 - 6 } & $2.26 \%$ & $2.60 \%$ & $6.93 \%$ & $3.02 \%$ \\
\hline
\end{tabular}

Fuente: Elaboración propia con base en datos de INEGI, disponible en http://www.inegi.org.mx/est/lista_cubos/consulta.aspx?p=adm\&c=8

El deficiente sistema de transporte público está conformado desarticuladamente por: Metro, Metrobús (sistema BRT), camiones (autobuses), microbuses y taxis individuales; la paradoja es que la gran mayoría de los desplazamientos metropolitanos se realiza en los vehículos de menor capacidad (Pradilla (coord.) y otros, 2015ạa: cap.5).

Desde el 2000, los gobiernos locales y el federal, presionados por el crecimiento del parque automotor, la saturación del tránsito y la contaminación atmosférica, han privilegiado la inversión en obras viales, descollando las autopistas urbanas confinadas, soterradas o elevadas, construidas y administradas mediante asociaciones público-privadas; las inversiones en medios sustentables de transporte público han sido inferiores a las viales e insuficientes para recuperar el retraso y atender las crecientes necesidades derivadas del incremento poblacional. El efecto 
de esta política de movilidad ha sido la promoción del uso del automóvil privado que satura rápidamente las nuevas vialidades y entorpece aún más el desplazamiento del transporte público de superficie.

Otros efectos de la proliferación de automóviles han sido: la saturación de la vialidad metropolitana incapaz de sustentar a la masa de automotores, la reducción de la velocidad promedio de circulación, y una intensa contaminación atmosférica. La movilidad en la metrópoli enfrenta una grave crisis que difícilmente podrá resolverse si continúan las políticas públicas que priorizan al transporte automotor privado.

\section{La polarización y la fragmentación socio-territorial}

A pesar del multimillonario gasto público en su combate, la pobreza en México, medida en porcentaje de la población total, se ha mantenido casi invariable desde finales de los años setenta del siglo XX (Gráfico 1). La caída del salario real de los trabajadores en 2012 a un 31,39 \% de su valor en 1980, la persistencia del desempleo masivo, el que un $60.1 \%$ de la población ocupada en 2012 lo hiciera en actividades informales recibiendo bajos e inestables ingresos, y la ausencia de acceso a la seguridad social de más del 60 \% de la población total, son factores determinantes de la pobreza imperante. 


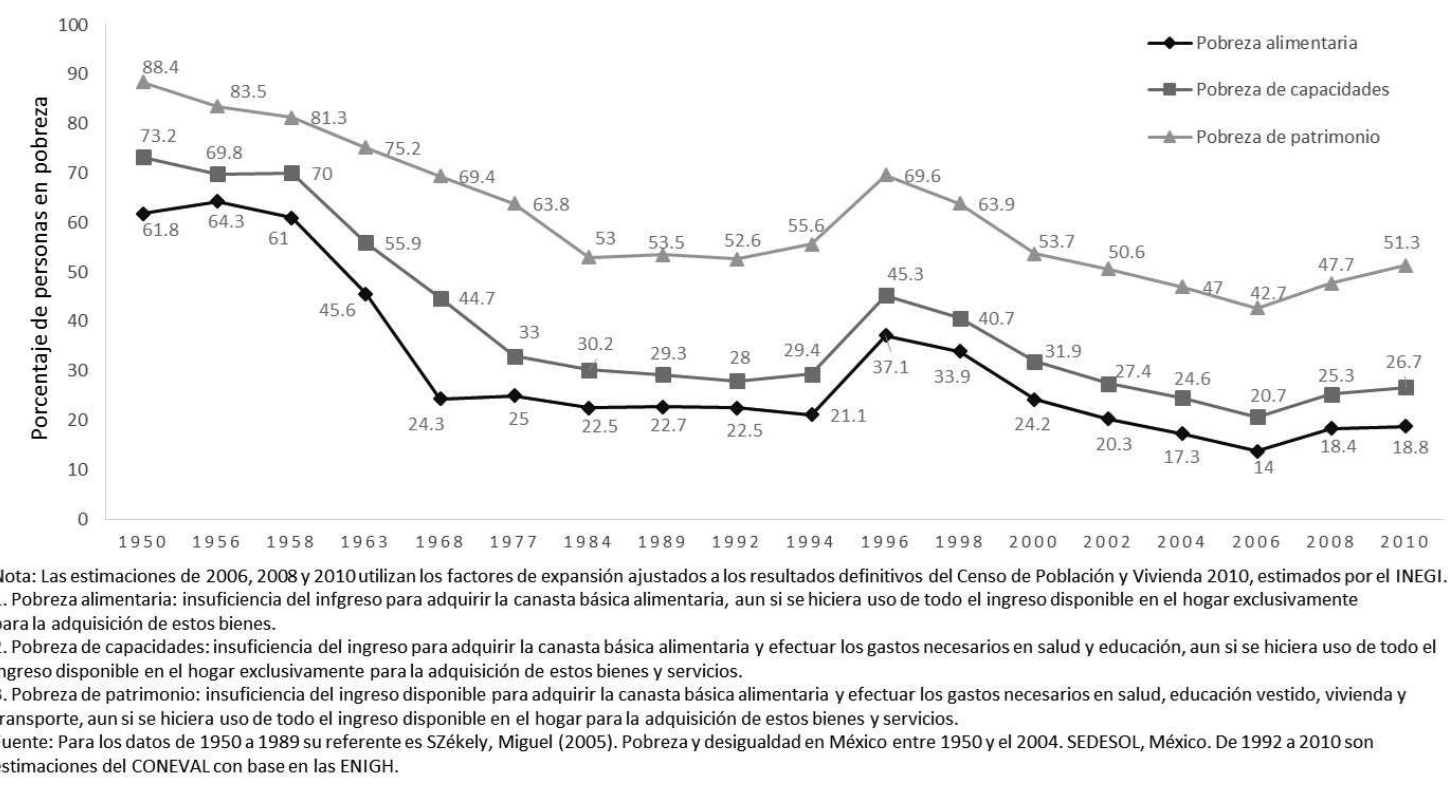

Aunque la situación de pobreza en términos relativos en la ZMVM es un poco menos grave que en el país en su conjunto, la gran masa de población que habita en ella la convierte en la mayor concentración de pobres del país (cuadro 8). En este aspecto, la metrópoli está sujeta a las mismas situaciones estructurales que el país en su conjunto (Pradilla et al., 2015 : cap. 1).

La polarización social en la ZMVM se ha expresado históricamente bajo la forma de una segregación residencial en términos territoriales que, en lo general, responde a un esquema centro-periferia, donde el centro ampliado, bien dotado de infraestructuras y equipamiento, servicios sociales y culturales, abasto mercantil y otras condiciones materiales de vida, ha sido ocupado por las capas de ingresos medios y altos, mientras que la periferia distante, carente de estas condiciones, en gran parte producida mediante la ocupación irregular de terrenos y la autoconstrucción de viviendas precarias, ha sido habitada por los sectores de más bajos ingresos (Rubalcava y Schteingart, 2012; Pradilla (coord..) y otros, 2015 : cap. 2). 
Cuadro 8

Incidencia de pobreza por el MMIP, Nacional, Urbano ${ }^{a}$, Metropolitano $\left(\sin\right.$ DF) ${ }^{b} y$ DF, 2008 (porcentaje de población)

\begin{tabular}{lcccc}
\hline \multicolumn{1}{c}{ Estrato del MMIP } & \multicolumn{4}{c}{ Metropolitano } \\
\hline 1. Indigentes & Nacional & Urbano & (Sin D.F.)b & D.F. \\
2. Muy pobres & 34.4 & 25.3 & 18.7 & 16.6 \\
3. Pobres moderados & 17.3 & 18.0 & 17.4 & 16.3 \\
Pobres no indigentes (2+3) & 27.5 & 31.1 & 33.6 & 31.7 \\
Total de Pobres (1+2+3) & 44.7 & 49.0 & 51.0 & 48.0 \\
4. Vulnerables (SANBRIT)C & 79.1 & 74.4 & 69.7 & 64.6 \\
5. Clase media & 10.5 & 12.9 & 15.0 & 15.9 \\
6. Clase alta & 8.2 & 10.1 & 12.3 & 14.1 \\
No pobres (4+5+6) & 2.1 & 2.6 & 3.0 & 5.5 \\
Total & 20.9 & 25.6 & 30.3 & 35.4 \\
\hline a & 100.0 & 100.0 & 100.0 & 100.0 \\
\hline
\end{tabular}

${ }^{a}$ Localidadesd de 2,500 o más habitanrtes

${ }^{\text {b }}$ Localidades de 100,000 o más habitantes, para fines de comparación no se incluye el DF

${ }^{c}$ Se refiere a la población que tiene satisfechas todas sus necesidades, pero en hasta $9.99 \%$ de la norma, por lo que pueden estar en riesgo de pobreza (anexo metodológico)

Fuente: Cálculos propios con base en las ENIGH, 2008, INEGI, Tomados de Damián, 2011: 8

Las transformaciones urbanas de las últimas tres décadas han añadido nuevos factores a la segregación socio-territorial: el aumento especulativo de los precios del suelo y la vivienda nueva en las áreas centrales; la verticalización como proceso de sustitución inmobiliaria y social en barrios de vivienda degradada; el desalojo de la población de bajos ingresos de las áreas centrales por la reestructuración terciaria; la segmentación territorial del mercado de bienes y servicios; y la elevación de los costos de vida en la metrópoli, incluyendo el del transporte debido al alargamiento de los desplazamientos. Por su parte, la intensa construcción de vialidades confinadas, soterradas, elevadas y distribuidores viales, etc., ha acentuado la segmentación social del territorio, convirtiéndola en 
Sociologias, Porto Alegre, ano 18,no 42, mai/ago 2016, p. 54-89

una verdadera fragmentación llena de barreras a la libre circulación y de factores de exclusión social.

\section{La fragmentación político-administrativa y las políticas urbanas}

Desde que se inició el proceso de metropolización en los años cuarenta del siglo XX, la metrópoli está fragmentada en su organización político-administrativa en dos entidades federales: la ciudad de México, su núcleo central; y los municipios conurbados del Estado de México; más recientemente, empezó la integración de municipios del Estado de Hidalgo a la metrópoli. A nivel local, en la delimitación territorial que asumimos, la ZMVM está formada por 16 delegaciones de la Ciudad de México DF y 60 municipios conurbados de los estados de México e Hidalgo, lo cual añade un grado mayor de fragmentación de la administración pues este nivel de gobierno tiene funciones específicas de gestión territorial como la planeación y el control del desarrollo urbano (Pradilla y Sodi, 2006: 254-270).

A pesar de los múltiples procesos y problemas comunes surgidos de la articulación del mosaico de UPA en un solo sistema urbano (Pradilla y Sodi, 2006: 258 y ss.), en los dos niveles de gobierno estos fragmentos tienen atribuciones propias de administración y gestión territorial, lo cual conduce a descoordinación en el tiempo y el territorio, duplicidades, oposiciones y conflictos entre las políticas de todo tipo elaboradas y aplicadas por cada parte. Los instrumentos de coordinación metropolitana contenidos en la legislación ${ }^{15}$ desde hace 4 décadas, han sido totalmente insuficientes e ineficaces para lograr acciones convergentes y unitarias de gestión del desarrollo económico, social y urbano en este mosaico de partes. Todas las propuestas para intensificar y mejorar los instrumentos de

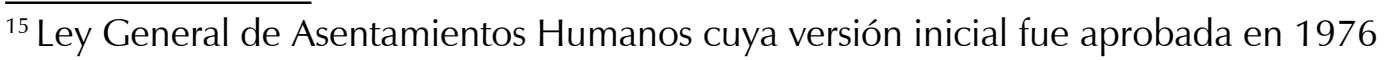


coordinación metropolitana, o para crear alguna forma de gobierno metropolitano han sido ignoradas por la fracción dominante en el Congreso Nacional, la del Partido Revolucionario Institucional (PRI).

La historia político-electoral ha actuado como agravante de la fragmentación objetiva de la metrópoli. En las últimas dos décadas, los fragmentos estatales de la gestión metropolitana han sido gobernados por partidos políticos formalmente diferenciados o contrapuestos: el centro-izquierda del Partido de la Revolución Democrática gobierna a la Ciudad de México DF desde 1997, cuando venció al PRI en la primera elección democrática de su gobernante ${ }^{16}$; y el centro-derecha del Partido Revolucionario Institucional ha gobernado ininterrumpidamente a los dos estados vecinos durante todo el período posrevolucionario. En los fragmentos locales, la diversidad de partidos políticos gobernantes ha sido mayor, con la presencia adicional de la derecha del Partido Acción Nacional. La coexistencia de partidos políticos en competencia por el poder, es parte de la pluralidad democrática, pero por la ausencia de mecanismos reconocidos y eficaces de coordinación metropolitana, se agudizan las contradicciones y conflictos entre las políticas fragmentarias.

En este contexto de fragmentación, descoordinación y oposición de la gestión de las partes del todo metropolitano, las políticas urbanas aplicadas en ellas tienen similares características generales: ausencia o no aplicación de la planeación urbana de mediano y largo plazo ${ }^{17}$, sustitui-

\footnotetext{
${ }^{16}$ Durante siete décadas y hasta 1997, el Distrito Federal fue una dependencia administrativa del gobierno federal, lo gobernaba un Regente designado por el Presidente de la República; solo en diciembre de 2015 se aprobó una reforma constitucional que elimina el Estatuto de Excepción de la Ciudad de México y le otorga condiciones de igualdad con el resto de entidades estatales del país.

${ }^{17}$ Mientras en el Distrito Federal la ley mandata a elaborar programas generales de desarrollo urbano, programas delegacionales y parciales periódicos, en los municipios conurbados en la ZMVM, los programas de desarrollo urbano los realiza cada municipio y no se elabora un instrumento de planeación para el conjunto de los municipios metropolitanos.
} 
da por políticas coyunturales de corto plazo definidas para cada período gubernamental en cada fragmento; el diseño puntual y la realización de mega-proyectos urbanos públicos, privados o en asociación entre ambos sectores; carencia de instrumentos suficientes para la aplicación de la planeación realmente existente derivada del adelgazamiento estatal y la desregulación neoliberales; tendencia ideológica y práctica a la privatización y mercantilización de todo lo urbano; un acendrado pragmatismo que otorga el papel motriz en el desarrollo urbano al capital inmobiliario-financiero privado trasnacionalizado; y un discurso formal modernizador y especulativo, que busca el crecimiento económico a toda costa, la generación de empleo así sea temporal y mal pagado, la "competitividad global" y el prestigio simbólico (Pradilla, 2015b).

Una de las justificaciones para la asociación público-privada, que no mide sus implicaciones de control privado sobre lo público ni los efectos depredadores de la lógica de la ganancia mercantil sobre los ingresos populares, es la ausencia de recursos presupuestales suficientes del sector público para financiar la modernización urbana. Los ejemplos más importantes de esta asociación han sido los segundos pisos viales de cuota, el transporte público de pasajeros, y la modernización del espacio público, en ambas partes de la metrópoli, sin que el distinto sello ideológico-político declarado de sus gobernantes establezca mucha diferencia. Así, los gobiernos locales actúan como facilitadores subsidiarios de las acciones privadas de construcción y reconstrucción de la metrópoli. De esta lógica privatizadora no han escapado los gobiernos "de izquierda" del Distrito Federal (Pradilla, 2015 b). 


\section{Los movimientos sociales en y por la ciudad}

Como capital de la república y asiento de los poderes federales en su núcleo de la Ciudad de México DF, la metrópoli es el lugar de despliegue de intensos y numerosos movimientos sociales que se manifiestan en la ciudad, generados por múltiples procesos conflictivos ocurridos en todo el país ${ }^{18}$, pero que afectan notoriamente su funcionamiento cotidiano, en particular la movilidad vehicular. Simultáneamente, la ZMVM es el escenario de constantes movimientos sociales por la ciudad, cuyas causas y objetivos se relacionan directamente con las estructuras y procesos metropolitanos y con el mejoramiento de las condiciones materiales y sociales de vida de sus habitantes. El proceso de crecimiento y transformación urbana impuesto por las políticas públicas y las prácticas del capital inmobiliario-financiero luego de tres décadas y media de aplicación del patrón neoliberal de acumulación de capital, ha agudizado la conflictividad urbana, que se manifiesta tanto en la permanencia de los movimientos sociales gestados en las décadas de acelerado crecimiento de la metrópoli, como en la emergencia de nuevos movimientos sociales enraizados en las nuevas contradicciones del desarrollo urbano.

En las décadas de los años sesenta, setenta y ochenta del siglo XX, el movimiento social urbano en la metrópoli estaba dominado por la lucha de los sectores populares frente al Estado y los gobiernos locales por la conservación del suelo obtenido mediante la ocupación irregular o ilegal, para auto-construir sus viviendas, lograr la regularización de la propiedad, y obtener los servicios públicos esenciales (Schteingart, 1989: cap. II y

\footnotetext{
${ }^{18}$ Ejemplos recientes han sido las movilizaciones de los maestros disidentes de la Coordinadora Nacional de Trabajadores de la Educación (CNTE), y las realizadas periódicamente por los padres der los 43 normalistas plagiados el 26 de septiembre de 2014 en Ayotzinapa, Guerrero, y las organizaciones estudiantiles y sociales que los apoyan.
} 
III); fueron los años de despliegue del movimiento urbano popular (MUP) que en muchos casos llegó a adquirir altos grados de radicalidad política. Los sismos de 1985 detonaron una ola de movimientos sociales de damnificados que incidieron en el proceso de democratización de la capital e irrumpieron en la política partidista ${ }^{19}$.

Sin que desaparecieran las manifestaciones del movimiento urbano popular gestado en el período anterior, las últimas décadas, a partir de la aplicación de las políticas neoliberales y los sismos de 1985, han sido escenario de cambios fundamentales con la emergencia de nuevos movimientos sociales en y por la ciudad: a) la multiplicación de aquellos cuyos objetivos son variados (ecológicos, de género, democráticos, contra la violencia, por los derechos humanos, etc.), en los que participan muy diversos sectores y estratos sociales, y que tienen a la ciudad fundamentalmente como escenario; b) movimientos gremiales defensivos ligados a procesos específicamente metropolitanos como los trabajadores del transporte público en camiones o microbuses, de otros servicios públicos sujetos a intervenciones estatales, o del comercio informal en la vía pública; у c) un incremento de los movimientos sociales urbanos defensivos, en los que participan cada vez más, las capas medias y, aún, altas de la sociedad en sus áreas habitacionales, cuyo patrimonio y habitabilidad se ven amenazadas por las acciones de los gobiernos locales, las del capital inmobiliario-financiero y las desarrolladas conjuntamente en las asociaciones público-privadas (Pradilla y Moreno, 2015). Sin embargo, estas tres vertientes del movimiento urbano actúan aisladamente, cada una por sus demandas, sin coincidencias en el tiempo y los territorios.

\footnotetext{
${ }^{19}$ Las organizaciones urbanas populares surgidas en la Ciudad de México luego de los sismos de 1985, que jugaron un papel importante en la formación del Partido de la Revolución Democrática en 1989, y en muchos casos, se disolvieron en él.
} 
En estos ámbitos de conflicto social y urbano, sobre todo en el primero, han irrumpido con creciente fuerza las Organizaciones No Gubernamentales, cuya actividad es fragmentaria pues responden a muy diferentes objetivos, tienen una representatividad social real muy desigual y son portadores de una muy diversificada ideología.

Lejos de resolver los conflictos urbanos, el nuevo modelo de desarrollo urbano impuesto por el patrón neoliberal de acumulación de capital y sus actores urbanos fundamentales, el capital inmobiliario-financiero y el Estrado facilitador y subsidiario, ha ampliado la conflictividad con diversos estratos sociales, incluyendo las capas medias y aún altas y sus organizaciones vecinales que como tales son defensivas, no son portadoras de posiciones políticas orientadas a la transformación estructural de la metrópoli.

\section{Reflexión final}

En la Zona Metropolitana del Valle de México, las tres y media décadas pasadas han sido de cambios estructurales y morfológicos, determinados por su expansión demográfica y física dispersa, desordenada y carente de orientación y regulación por un programa de desarrollo urbano metropolitano, y por los impactos económicos, sociales y territoriales derivados de la aplicación a nivel nacional, en momentos distintos, de las políticas neoliberales, las cuales actúan acumulativamente.

La desindustrialización absoluta y relativa, la terciarización dominada cuantitativamente por el trabajo informal, el desempleo abierto y la pobreza de masas aparecen como elementos constitutivos de la crisis económica y social de la metrópoli. Por su parte, el discurso neoliberal predica y practica como alternativas la mercantilización y la privatización de lo urbano, la lógica de la ganancia empresarial y el libre juego -no sujeto a la planeación- de los actores urbanos en el mercado, que son los 
vectores dominantes en el desarrollo metropolitano. La modernización urbana llevada a cabo por el capital inmobiliario-financiero, mediante sus nuevos artefactos, para competir en el mercado global, aparece como la fórmula para resolver la crisis metropolitana.

Pero lejos de aminorar las contradicciones urbanas, los cambios estructurales y formales de la metrópoli han modificado y agudizado los viejos conflictos que siguen afectando primordialmente a los sectores populares empobrecidos, y han generado otros nuevos producidos por la modernización inmobiliaria, los cuales han alcanzado también a las capas medias y, aún, altas de la sociedad. La metrópoli más grande e importante de México, se encuentra enfrentada a una crisis permanente, agudizada notoriamente por la situación de violencia extrema a la que el crimen organizado ha sometido al país en los últimos años.

Las políticas urbanas del gobierno federal y de los gobiernos locales de las partes de la metrópoli, pragmáticas, descoordinadas y contradictorias, preñadas de justificaciones derivadas del discurso de la globalización neoliberal, no son resultado de la planeación de mediano y largo plazo, si no de la lectura subjetiva y coyuntural de las razones del mercado y los intereses del capital, en particular el inmobiliario-financiero, a las cuales se someten los diversos poderes del Estado asumido como el facilitador subsidiario de sus acciones.

Los movimientos sociales por la ciudad, crecientemente pluriclasistas, cuya ingeniosidad y uso de las nuevas tecnologías va en aumento, actúan reactivamente a las acciones asociadas del capital y los gobiernos, sin coordinarse o integrarse alrededor de un proyecto alternativo de ciudad en el largo plazo, que desde luego no es impulsado tampoco por ninguno de los partidos parlamentarios del abanico ideológico formal que compiten por los distintos gobiernos metropolitanos (Pradilla (coord..) y otros, 2015': cap. 1). 
Esta ausencia de proyectos de ciudad, conservadores o alternativos, hace permanente e insoluble la crisis urbana y lleva a que la sociedad se desgaste en luchas coyunturales defensivas constantes, que no nos acercan a una meta de metrópoli sostenible y sustentable, en un momento en que los riesgos generados por el cambio climático, oscurecen los nubarrones que se ciernen sobre nuestra sociedad del despilfarro.

Emilio Pradilla Cobos: Doctor en Urbanismo. Profesor titular, Departamento de Teoría y Análisis, División de Ciencias y Artes para el Diseño, Universidad Autónoma Metropolitana, Unidad Xochimilco. Ciudad de México, México.

\epradillacrm@hotmail.com

\section{Referencias}

1. CONSEJO NACIONAL DE POBLACIÓN (CONAPO). Delimitación de las zonas metropolitanas de México 2005. México DF: SEDESOL, CONAPO, INEGI, 2007.

2. DUHAU, E. Los nuevos productores del espacio habitable. Ciudades, Puebla, n. 79, p. 21-27, jul./sep. 2008.

3. DUHAU, E.; GIGLIA, Á. Las reglas del (des)orden. Habitar la metrópoli. México DF: Siglo XXI, Universidad Autónoma Metropolitana, Azcapotzalco, 2008.

4. EIBENSCHUTZ, R.; GOYA, C. (Coords.). Estudio de la integración urbana y social en la expansión reciente de las ciudades en México, 1996-2006: dimensión, características y soluciones. México DF: Cámara de Diputados LX Legislatura, SEDESOL, Miguel Ángel Porrúa Editor, UAM-X, 2009.

5. GARZA, Gustavo. El proceso de industrialización en la Ciudad de México. 1821 - 1970. México DF: El Colegio de México, 1985.

6. GUILLÉN, Héctor. La contrarrevolución neoliberal. México DF: Ediciones Era, 1997.

7. HARVEY, D. Los límites del capitalismo y la teoría marxista. México DF: FCE, 1990.

8. HARVEY, D. Breve historia del neoliberalismo. Madrid: Akal, 2009.

9. HARVEY, D. Diecisiete contradicciones y el fin del capitalismo. Quito: Instituto de Altos Estudios Nacionales del Ecuador, 2014. 
10. INSTITUTO NACIONAL DE ESTADÍSTICA, GEOGRAFÍA E INFORMÁTICA (INEGI). Encuesta Nacional de Ocupación y Empleo. Aguascalientes: INEGI, 2012.

11. INSTITUTO NACIONAL DE ESTADÍSTICA, GEOGRAFÍA E INFORMÁTICA (INEGI). Estadísticas históricas de México. Aguascalientes: INEGI, 2013.

12. JARAMILLO, Samuel. Hacia una teoría de la renta del suelo urbano. Bogotá: Universidad de los Andes, 2009.

13. MÁRQUEZ, L.; PRADILLA, E. Desindustrialización, terciarización y estructura metropolitana: un debate conceptual necesario. Cuadernos del CENDES, Caracas, n. 69, p. 21 - 45, sept./dic. 2008.

14. MENDIBURU, Diego. Vivir en un gueto. Emeequis, México DF, n. 258, p. 25-30,11 julio 2011.

15. PIREZ, Pedro. La mercantilización de la urbanización. A propósito de los "conjuntos urbanos" en México. Estudios Demográficos y Urbanos. México DF, v. 29 , n. 3 (87), p. 481-512, 2014.

16. PRADILLA, E. Las políticas neoliberales y la cuestión territorial. Sociológica. México DF, Año 5, n.12, p. 47-73, enero-abril 1990.

17. PRADILLA, E. Territorios en crisis. México 1970 - 1982. México DF: Red Nacional de Investigación Urbana, Universidad Autónoma Metropolitana, Xochimilco, 1993a

18. PRADILLA, E. La contrarreforma agraria y la cuestión territorial. In: COORDINACIÓN GENERAL DE INVESTIGACIÓN Y ESTUDIOS AVANZADOS (Ed.). Memoria de la primera mesa redonda "Implicaciones de las reformas al Artículo 27 Constitucional y la nueva Ley Agraria". Toluca: Universidad Autónoma del Estado de México, p. 239 - 252, 1993b.

19. PRADILLA, E. Privatización de la infraestructura y los servicios públicos: sus contradicciones. Argumentos. México DF, n. 21, p. 57-79, dic. 1994.

20. PRADILLA, E. Los territorios del neoliberalismo en América Latina. México DF: Universidad Autónoma Metropolitana, Xochimilco, Miguel Ángel Porrúa Editor, 2009.

21. PRADILLA, E. Mundialización neoliberal, cambios urbanos y políticas estatales en América Latina. Cadernos métropole. Sao Paulo, vol.12, n. 24, p. 507 - 533, jul./dez. 2010.

22. PRADILLA, E. Zona Metropolitana del Valle de México: Una ciudad baja, dispersa, porosa y de poca densidad. In PRADILLA, E (Comp.). Ciudades compactas, dispersas, fragmentadas. México DF: Miguel Ángel Porrúa Editor, Universidad Autónoma Metropolitana, Xochimilco, p. 257 - 294, 2011. 
23. PRADILLA, E. La ciudad capitalista en el patrón neoliberal de acumulación en América Latina. Cadernos métropole. Sao Paulo, v. 16, n. 31, p. 37 - 60, jun 2014.

24. PRADILLA, E. De la ciudad compacta a la periferia dispersa. Ciudades, Puebla, n. 106, p. $2-9$, abr./jun. 2015a․

25. PRADILLA, E. Las razones del mercado y las políticas urbanas en la Zona Metropolitana del Valle de México. In: RAMIREZ, B. R.; EIBENSCHUTZ, R. (coord.). Repensar la metrópoli II. Tomo II. México DF: Universidad Autónoma Metropolitana, PUEM, p. $136-151,2015^{\text {b }}$.

26. PRADILLA, E; MÁRQUEZ, L.; CARREÓN, S.; FONSECA, E.. Centros comerciales, terciarización y privatización de lo público. Ciudades, Puebla, n. 79, p. 44-53, jul./sept. 2008.

27. PRADILLA, E.; MORENO, F. de J. Conflictos, movimientos sociales y política urbana en la Zona Metropolitana del Valle de México 1980-2011". In: CASTILLO, I.; ORNELAS, J.; HERNÄNDEZ, C. (coords.). Zonas Metropolitanas. Reflexiones teóricas y estudios en el centro del país. México DF: Universidad Autónoma de Tlaxcala y Miguel Ángel Porrúa Editor, P. 75 - 102, 2015.

28. PRADILLA, E.; PINO, R. A. Ciudad de México: de la centralidad a la red de corredores urbanos. Anuario de Espacios Urbanos 2004, México DF, UAM-A, Gernika, p. 69 - 96, 2004.

29. PRADILLA, E. (Coord.); PINO, R. A.; MORENO, F de J.; DÏAZ, L. O.; HERNÁNDEZ, C.; NEMETH, F. G.; SANTIAGO, C.; VALDERRAMA, C.. Zona Metropolitana del Valle de México: cambios demográficos, económicos y territoriales. México DF: Proyecto CONACYT-UAM parte I, inédito, 2015a‥

30. PRADILLA, E. (Coord.); PINO, R. A.; MORENO, F. de J.; BARRERA, H.; DÏAZ, L. O.; HERNÁNDEZ, C.; MARIN, F. F.; SANTIAGO, C. Zona Metropolitana del Valle de México: cambios sociales. México DF: Proyecto CONACYT-UAM parte II, inédito, $2015^{\mathrm{b}}$.

31. PRADILLA, E. (Coord.); PINO, R. A.; MORENO, F. de J.; BARRERA, H.; DÏAZ, L. O.; GARCÏA, E.; HRTNÄNDEZ, C.; MARÏN, F. F.; SANTIAGO, C.. Zona Metropolitana del Valle de México: las políticas urbanas metropolitanas. México DF: Proyecto CONACYT-UAM parte III, inédito, $2015^{c}$.

32. PRADILLA, E.; SODI, D. La ciudad incluyente. Un proyecto democrático para el Distrito Federal. México DF: Océano y Oidme, 2006.

33. PUEBLA, C. Del intervencionismo estatal a las estrategias facilitadoras. Cambios en la política de vivienda en México. México DF: El Colegio de México, 2002. 
34. RUBALCAVA, R. M.; SCHTEINGART, M. Ciudades divididas. Desigualdad y segregación social en México. México DF: El Colegio de México, 2012.

35. SALAMA, P. Globalización comercial: desindustrialización prematura en América Latina e industrialización en Asia. Comercio Exterior, México DF, v. 62, N. 6, p. $34-44$, nov./ dic. 2012.

36. SCHTEINGART, M. Los productores del espacio habitable. Estado, empresa y sociedad en la Ciudad de México. México DF: El Colegio de México, 1989.

Recebido em: 12/02/2016

Aceite Final: 10/04/2016 